\title{
The Research on The Basic Modeling Education of Design Universities
}

\author{
Meiying Yin \\ Shanghai University of Engineering Science \\ Shanghai, China
}

\begin{abstract}
Basic education is the most fundamental thing in design education. That is to say, is it suitable for colleges to stick to the repeated painting learning education when training innovative thinking if they were already familiar with it? Does this consistent way of education limit the students' ability of creative thinking? Does it really help when discussing how to solve the problems such as modeling and solving problems, and how to help students' creative thinking? By understanding the Bauhaus education idea and the analyze the famous Bauhaus educator, this thesis will explore the fundamental education of Bauhaus on how it carries out, do a comparative analysis on the development of Britain, the United States, and South Korea's basic design education, and explore the new basic education method of modeling design in China universities.
\end{abstract}

Keywords-design, basic modeling education, Bauhaus, creativity

\section{INTRODUCTION}

China's design colleges lack of systematic education on the basis of the design education and the development of students' creativity and basic performance. On this issue, because Bauhaus is recognized as the world's first school that lays the foundation in designing the perfect course system, this paper is devoted to the study of basic modeling education of the Bauhaus, and makes a comparative study between China and Bauhaus to explore issues related to existing education teaching, and puts forward a new attempt. Based on the analysis of Bauhaus's basic education, this paper probes into the research of the thinking education in the modeling course of the basic design education in China's design colleges. Comparisons will be made with the United Kingdom, the United States and South Korea to figure out in which part they do great job in the design of basic education courses in Colleges and universities compared with China. Emerging design practices are changing and expanding to create a complex and ambiguous subject environment. This has a direct impact on the field of design education, thus calling for a new flexible model to address the needs of future practitioners, unknown markets and emerging social culture [1].

\section{BAUHAUS BASIC MODELING EDUCATION}

Bauhaus basic education enables students who are new to design learn the basic knowledge, and the purpose is to enable students to learn and quickly grasp the shape of the material and related technologies. In Bauhaus founder and President Walter Gropius's work, the Bauhaus Declaration, it can be seen that "emphasis on craft, technology and art of harmony and unity" was the idea he had long been held. In order to achieve this goal, he carried out a series of educational reform, based on the training methods of Arts and crafts. Through the art of training, students can achieve a reasonable level of visual sensitivity. In the part of basic education, its scope includes architecture, painting, sculpture and some other related fields. Students should accept the craft, drawing, painting, science and some other theoretical training. Education curriculum is divided into Course for Apprentices, Course for Journeymen, and Course for Junior Masters. Those are a combination of art and technology. In medieval apprenticeship system, a person can become a technician, an artist and a businessman.

At first, the Bauhaus "form tutor" Johannes Itten stressed the importance of basic education. He thought that compared with studying science and technology from the perspective of the material, spiritual thinking and soul power is what should be came up with first, which can make contributions to the construction of civilization system. His teaching is often the mix of religion and science visual effects education, which leaves both negative and positive influence for students. He make the students directly contact with various material to let them percept and express the material contrast and difference. In this way, his curriculum is divided into three categories [2]. The first one is the study of natural materials. The second one is the use of charcoal to show the great changes in light, shade and rhythm through the human body drawing in the grasp of the characteristics of the human body. By that point, line, plane, three-dimensional, scale, texture, and color are the repeated rhythm of the life theme. With the point of view of "Great power comes from the rhythm", the study of rhythm is also one of the subjects. The third is the appreciation of the works of the famous. In 1963, Eaton wrote about Bauhaus's basic curriculum, he thought the Bauhaus basic curriculum was designed to understand the 
potential creativity of students and inspire them. Figure 1

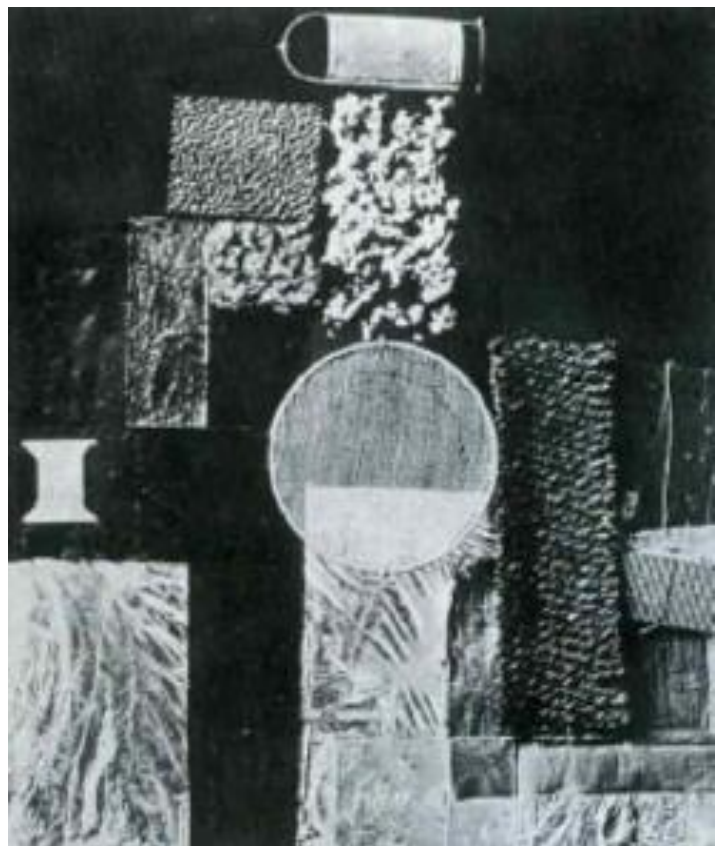

Fig. 1. Comparison of various materials

The preparatory courses are set up by Laszlo Moholy-Nagy. They practically carried out the space on the ground, and through the study of three-dimensional shape, structure, balance, spatial learning, thus improving students' sense of space and imagination, and makes it an education policy [3]. Through the training for symmetrical balance aesthetics, and the use of glass, plastic, wood, metal, wire and other complex shapes of modeling, a variety of commonly used vertical and horizontal structure of asymmetrical shape of objects are used, which deepens the students' understanding of balance in both space and weight. This kind of education enables students to deepen the understanding of materials, and through this learning experience, students are well-guided to make good design and research.

Wassily Kandinsky's modeling theory is based on the compact between the level of opposition to the diagonal and the vertical form, in order to set up the courses for abstract form elements analysis. The main purpose of Kandinsky teaching approach and the ultimate goal are as follows: first, on the internal value and external value, the analysis of painting elements; second, the relationship between elements of painting, other artistic value and natural value; third, the composition of painting elements, and the appropriate topic type; fourth, the relationship between these elements, other art form, and nature. In the main contents of Kandinsky's curriculum, the education of object analysis is all in the tables, chairs, and ladder. Through the analysis of morphological, these characteristics are reduced to a single form, the study presents a variety of relations in the structure, through multiple lines. shows the comparison of various materials.

\section{COMPARISON OF THE BASIC EDUCATION BETWEEN CHINA,}

\section{UNITED KINGDOM, THE UNITED STATES AND SOUTH KOREA}

At the beginning of the 80 s, the Bauhaus basic education, which was introduced into China through Hong Kong, was developed into an education system called "three components". Guangzhou Academy of Fine Arts, Central Academy of Fine Arts and some other specialized design universities firstly opened the structural subjects, and the modeling elements were applied into the design, thus an education system began to form. Three major subjects become a required professional basis for all design courses. This is a direct introduction to the Bauhaus education system. The three components include the plane structure, color composition and three-dimensional composition, which play an important part in the basic modeling education.

Bauhaus education concept is based on the modeling curriculum as a guide to the basic learning form. In order to study the basic modeling, it uses a variety of materials, which enables students to experience the physical properties in visual and tactile, stimulates students' potential ability of shaping, and not ties them to fixed ideas, but let the students have their own understanding in foundation works. On the basis of a similar educational philosophy, take its essence to its dregs, the spread of contemporary educational ideas is throughout the world [4]. At present, the basic modeling education is in order to cultivate the creative sense of the modeling, as well as the ability and the right attitude to solve the problems. The study of Bauhaus's basic education curriculum is embodied in the plane and three-dimensional structure. This is the first time that the basic theory of design is used in the field of science, and the basic system of design is perfectly built. This is a phenomenon that has never existed before the establishment of Bauhaus.

The diversity and integrity of the Bauhaus basic education emphasizes the combination of technology and theory. However, the Three Major Components in China have only introduced some simple analysis of points, lines and surfaces, and they have not been used in the practical application. In terms of Bauhaus basic education subjects, "the natural analysis", "research on modeling, space, movement and perspective ", "systematical space research" and "visual training" and "color and geometry training" should not only be used in the works in class time, but also be the focus of the basic principle of science.

The content of the basic modeling education is based on the whole field of plastic arts, including modeling psychology, modeling method, visual perception theory and other related contents. The main elements of modeling include color, texture, and the elements of space include point, line, surface, half three-dimensional and three-dimensional space, the conditional elements include number, quantity, location, light, action, etc. The basic modeling education is an organic combination of these things above. Students of design major should be proficient in mastering the basic modeling education and developing the ability of thinking and expressing. Using the skills you learnt 
to develop your own plans and develop your creativity, and achieve a sense of accomplishment after you finish your work. For the education of modeling elements, in the process of students' understanding of the elements of modeling, a careful observation of nature will be of some help. The basic training of modeling is not only the training of modeling ability, but also the aesthetic education [5].

I have made a detailed comparison between China and the United Kingdom, the United States and Korea, and found out that the relationship between nature and diversity of materials, the texture of the understanding, the importance of communication and psychological research on specific part are rarely involved in other basic education in China. Different from the United Kingdom and the United States, which see the performance, application ability, thinking ability as the center of the organic composition of the basic education, the basic education of China's colleges and universities until now is not complete. In the United Kingdom, it is more emphasized on the cultivation of natural feelings, and in the United States it has a similar interpersonal communication and psychology into the basic shape of the subject. Students of design major in the United States learn basic courses of 2D, 3D and other subjects, including the ability to develop a natural expression. When students are in the start production of the film, when they are in the cooperation with publishers and film companies, they understand and master the theme and meaning, problems and purposes, as well as the relevant knowledge of image production. These courses are not only the help of the basic education curriculum, but also the practical application process. In South Korea, emphasis is on observation and expression, while in China, we more emphasize the traditional culture, and focus on specific performance [6].

TABLE I COMPARISON BETWEEN CHINA AND THREE OTHER COUNTRIES ON BASIC MODELING EDUCATION

\begin{tabular}{|c|c|c|}
\hline Nation & Basic modeling education & Characteristic \\
\hline China & $\begin{array}{l}\text { Uses sketch and color based modeling education as the } \\
\text { main subjects, so students can find themselves and have } \\
\text { a correct understanding for the composition of things, } \\
\text { and focus on the development of painting techniques. }\end{array}$ & $\begin{array}{l}\text { Pay attention to the correct } \\
\text { understanding of the structure } \\
\text { of things, emphasizing } \\
\text { painting techniques. }\end{array}$ \\
\hline UK & $\begin{array}{l}\text { Allows students to have access to a variety of materials, } \\
\text { and it is committed to cultivating students' perception of } \\
\text { nature, strengthening the training of abstract } \\
\text { performance. }\end{array}$ & $\begin{array}{l}\text { Students come into contact } \\
\text { with a variety of materials } \\
\text { through the K-12 stage system } \\
\text { of learning basic education. }\end{array}$ \\
\hline US & $\begin{array}{l}\text { Emphasizes the abstract performance, at the same time, } \\
\text { the combination of basic modeling subjects and } \\
\text { practical experience. Emphasis on creativity, while } \\
\text { interpersonal communication and psychology are added } \\
\text { into the basic modeling subjects. }\end{array}$ & $\begin{array}{l}\text { Pay attention to the creativity } \\
\text { of students, promote the } \\
\text { imagination and tap the } \\
\text { potential ability of the } \\
\text { challenge. }\end{array}$ \\
\hline NK & $\begin{array}{l}\text { Attaches great importance to observation and } \\
\text { expression, through the understanding and application } \\
\text { of the various modeling elements and their principles, } \\
\text { creative and experimental spirit are cultivated, and train } \\
\text { each student's personality according to this. }\end{array}$ & $\begin{array}{l}\text { Emphasis on Modeling and } \\
\text { performance, pay attention to } \\
\text { creativity. }\end{array}$ \\
\hline
\end{tabular}

As can be seen in table.1, the common characteristics of the basic modeling education in China and three other countries can be found. The basic modeling education needs to combine a variety of thinking methods and training courses, so as to make the creativity concrete.

\section{CONCLUSION}

Chinese basic modeling education nowadays continues the education method of Bauhaus, while for the development of basic modeling education of Chinese design colleges, they cannot copy the methods of developed countries, cannot only maintain the traditional way they are holding now. Therefore, it is necessary to explore a new model of basic modeling education, which is of practical and developing significance to the future. Therefore, it is necessary to make a new attempt to develop the basic modeling education which can adapt to the modern society of china. In this study, based on this fundamental problem, the following improvements are proposed.

Chinese colleges and universities need to refer to the experience of developed countries in the basic modeling courses for the experience of natural materials and perception of education. Lack of experience in the use of various materials as well as students" full understanding of 
the texture, China's colleges and universities only use it in the introduction of professional courses, and has been negligent to the following. It is necessary for students to come into contact with more materials. China has a short history in carrying out basic modeling education, and cannot fully absorbed the essence of the Bauhaus design education system, and has not yet explored an suitable education system that is China-based characteristic and suitable for the current situation. Besides, as for the specific content of education, thorough study on the modern modeling language system in Europe and the United states is missing. In the future, China should promote the exchange of International Studies and the direct communication between different countries. Most of the students before entering university only receive training for The Three Components, namely only stay in the stage of specific description of still life sketch and color etc., so they cannot come into contact with the expression for abstract modeling.

Therefore, the focus of China's basic modeling subjects should be exchanged from the student's reproduction from the specific phenomenon into the expression of abstract imagination. And over-strict basic modeling education will limits students' freedom of creativity and imagination, thus leading to the decrease of modeling in different degrees, so in the early stage of basic modeling education, schools should give priority to cultivating students' passion for design.

\section{REFERENCE}

[1] Shouzhi Wang, World modern design history, The China Youth Publishing House, 2002, p.145. in chinese

[2] Johannes Itten,Op.cit,p.98.

[3] Ping Ke. Research on the problem of modeling basic education [D] China Central Academy Of Fine Arts,2013. in chinese

[4] Timon B. Heinis,Ina Goller,Mirko Meboldt. Multilevel Design Education for Innovation Competencies[J]. Procedia CIRP,2016,50:

[5] Colleen E. Mills. Navigating the interface between design education and fashion business start-up[J]. Education + Training,2012,54(8):

[6] The Emergence of an Amplified Mindset of Design: Implications for Postgraduate Design Education[J]. Mafalda Moreira,Emma Murphy,Irene McAra - McWilliam. Int J Art Des Educ. 2016(3) 